\title{
Effects of Dispersant and ZDDP Additives on Fretting Wear
}

\author{
A. Kontou ${ }^{1}$ (D) R. I. Taylor ${ }^{2} \cdot$ H. A. Spikes ${ }^{1}(\mathbb{D}$
}

Received: 14 June 2020 / Accepted: 10 November 2020 / Published online: 8 December 2020

(c) The Author(s) 2020

\begin{abstract}
This paper examines the effect of dispersant and anti-wear additives on fretting wear in lubricated bearing steel contacts. Reciprocating sliding ball-on-flat fretting tests with a stroke length of $50 \mu \mathrm{m}$ have been carried out on steel-to-steel contacts in both dry and lubricated conditions. Wear and friction coefficient have been measured, and surface characterisation has been carried out using optical techniques to investigate fretting wear. The presence of base oil reduces fretting wear markedly compared to dry conditions, but fretting damage is still observed at low reciprocation frequencies. As frequency is increased, there is a transition from oxidative to adhesive/scuffing damage. The anti-wear additive ZDDP is effective in forming a tribofilm on the surfaces and reducing visible oxidation and wear. A succinimide dispersant also reduces the accumulation of solid debris but does not alleviate wear damage. The combination of both ZDDP anti-wear additive and dispersant in base oil appears to provide significant protection against fretting wear.
\end{abstract}

Keywords Fretting wear $\cdot$ Fretting $\cdot$ Wear $\cdot$ ZDDP $\cdot$ Boundary lubrication $\cdot$ Dispersant $\cdot$ Lubrication

\section{Introduction}

When surfaces rub together in very low-amplitude oscillation, they may experience fretting damage. This can be a problem with many engineering components that experience vibration or repeated flexure, including couplings, bearing/ housing interfaces, piston rings and wire ropes. Fretting wear can occur in the rolling bearings of machines transported by sea, where it is often termed "false brinelling", while frequent start-stop to improve fuel consumption can enhance fretting wear in combustion engine components. In electric vehicles, the absence of a combustion engine can lead to different vibration patterns from those in which an engine is present, and lead to unexpected fretting damage.

H. A. Spikes

h.spikes@imperial.ac.uk

A. Kontou

artemisk@hotmail.co.uk

R. I. Taylor

robert.i.taylor@shell.com

1 Tribology Group, Department of Mechanical Engineering, Imperial College London, London, UK

2 Shell Global Solutions Ltd, Shell Centre, York Road, London SE1 7NA, UK
There is some confusion in the literature regarding the definition of fretting and the different types of damage it produces. According to Waterhouse, "fretting is the relative oscillatory tangential movement of small amplitude which may occur between contacting surfaces subjected to vibration" [1]. The terms fretting damage and fretting wear describe the harmful results of this fretting motion. The former refers to any form of material damage accumulation, while the latter is used when the damaging effect is assessed according to the amount of material removed from the surface. Fretting fatigue is the formation of fatigue cracks due to the cyclic stresses resulting from fretting [1] and fretting corrosion is a wear process in which chemical or electrochemical reaction involving water predominates in causing fretting damage [2].

Godfrey has distinguished two types of fretting damage, fretting corrosion which he associated with dry contacts, and false brinelling, seen with lubricated ones [3]. However this distinction is by no means universally accepted-for example, fretting corrosion is very often used to describe damage to metallic orthopaedic implants lubricated by aqueous solutions [4], while the term false brinelling tends to be confined to fretting wear seen in rolling bearings. The current paper describes a study of fretting wear in oil-lubricated contacts subjected to small amplitude oscillation. 
Vingsbo and Soderberg identified three distinct regions of tangential movement based on dynamic measurements of reciprocating tangential force and consequent displacement [5]. They characterised these regions as follows: (a) stick, where the interface is maintained under stick conditions; (b) partial slip, where slip is introduced in an annular slip area and fretting fatigue is dominant and (c) gross slip, where there is a rapid drop in the tangential force and kinetic motion starts to occur between the two bodies across the whole contact. Fretting wear occurs in the partial and gross slip regimes but only as long as the amplitude of displacement is less than the contact diameter. If the displacement amplitude is greater than this, the resulting wear is called sliding wear and the wear coefficient becomes independent of the amplitude [6].

One characteristic of fretting wear is the accumulation of wear debris in the form of very fine powder in and around the fretting contact. If the fretting materials are ferrous, this consists of red-brown or black iron oxides comprising, depending on the rubbing conditions, the various forms of $\mathrm{Fe}_{2} \mathrm{O}_{3}$ and also $\mathrm{Fe}_{3} \mathrm{O}_{4}$ [7]. This material is generally believed to accumulate close to the contact because the low-amplitude oscillation means that it is not displaced far from the contact and it has been suggested by many researchers to influence the fretting wear process itself [2, 8-16]. In principle it can act as a hard abrasive material within the contact to promote wear but it may also act as a protective lubricating third body to limit wear [17].

Fretting wear is a complicated process and studies have shown that frequency [18-21], slip amplitude [22-24], temperature [25-32], oxidation and oxygen supply at the surface [8-12], retention/ejection of debris from the contact [8, 13-16], contact pressure [33], tangential force, surface roughness [34-37] and hardness [13] of the contacting surfaces all play important roles in determining the severity of the fretting wear process. In practical systems often little can be done to change many of the above factors. However, the rubbing materials and the lubricant formulation are two features that can be manipulated to control fretting wear. Liquid lubricants such as oils and greases can reduce the coefficient of friction between contacting surfaces in the boundary lubrication regime and hence reduce fretting wear [1]. Another way that lubricants can help reduce fretting wear is by restricting oxygen supply into the contact and therefore reducing the formation of oxide debris [11]. The lubricant flow can also help remove solid particles from the contact [15].

A liquid lubricant's physical and chemical properties can be improved by adding lubricant additives. These additives include anti-oxidants, corrosion inhibitors, extreme pressure additives, dispersants and anti-wear agents. Two important oil additives are the dispersants and anti-wear additives. Dispersants disperse and suspend soot and other contamination particles in the oil, while anti-wear additives form a tribofilm (chemical film) during rubbing to protect the surface from adhesive wear. The most commonly used anti-wear additive is zinc dialkyldithiophosphate (ZDDP). According to Spikes [38], there are three main ways that ZDDP acts as an antiwear agent: (i) by forming a mechanically protective film [39], (ii) by removing corrosive peroxides or peroxy radicals $[40,41]$ and (iii) by "digesting" hard and thus abrasive iron oxide particles [42]. Neyman and Sikora [43] observed that the ZDDP additive in grease was effective in reducing fretting wear at a concentration of less than $1 \mathrm{wt} \%$. Similarly, Sato et al. [44] used tricresyl phosphate (TCP) and ZDDP at $2 \mathrm{wt} \%$ to study fretting wear and showed that even though TCP gave lower friction than ZDDP, ZDDP was more effective in reducing fretting wear. Recently, Grahn et al. [45] have also shown that ZDDP can reduce friction and wear in fretting contacts. Except for the above, there is little work to study the effect of ZDDP on fretting wear and the mechanisms involved are still not clearly understood.

Dispersant additives in lubricants reduce agglomeration of particles (especially soot) by steric stabilisation and can also prevent particles and debris from adhering to surfaces and so induce wear. Dispersants might therefore have a positive effect on fretting wear, where hard abrasive particles are believed to abrade the surfaces. There is little if any published research to date that examines the effect of dispersant on fretting wear. This paper aims to examine the effect on fretting wear of ZDDP and dispersant additives both separately and in combination. These additives are generally used together in engine oils, but dispersants are also used in automatic transmission fluids, while ZDDPs are employed in some greases, hydraulic oils and continuously variable transmissions. Ball-on-flat fretting wear tests were carried out using a high-frequency reciprocating rig (HFRR). Optical images, wear rates and friction coefficients were determined to establish the extent to which lubricant formulations containing ZDDP and dispersant additives reduce fretting wear.

\section{Experimental Method}

\subsection{Test Materials}

A gas-to-liquid (GTL) base oil with viscosity of $18.3 \mathrm{cSt}$ at $40{ }^{\circ} \mathrm{C}$ and $4.2 \mathrm{cSt}$ at $100{ }^{\circ} \mathrm{C}$ was used to formulate the lubricants. Two types of commercial lubricant additives were employed, a secondary ZDDP and a polyisobutylene succinimide (PIBSA) polyamine dispersant. Table 1 lists the additive details and the concentrations used. The concentrations of the additives in the oil were chosen according to the commercial usage in engine oils. The solutions were blended and stirred using a magnetic stirrer at $70{ }^{\circ} \mathrm{C}$ for $30-40 \mathrm{~min}$ until they were fully homogeneous. 
Table 1 Additives studied

\begin{tabular}{ll}
\hline Additive abbreviation & Additive details \\
\hline ZDDP & Secondary zinc dialkyldithiophosphate at $0.08 \mathrm{wt} \% \mathrm{P}$ \\
Disp & PIBSA polyamine dispersant at $0.02 \mathrm{wt} \% \mathrm{~N}$ (high MWt./ \\
& medium PIBSA functionality). Some tests also carried out at \\
& $0.1 \mathrm{wt} \% \mathrm{~N}$ \\
\hline
\end{tabular}

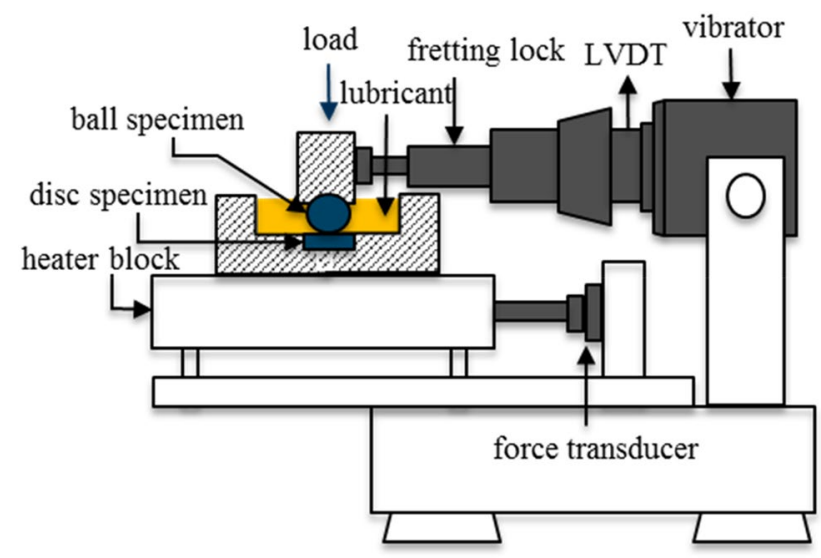

Fig. 1 Schematic diagram of HFRR

\subsection{Fretting Wear Tests}

Fretting tests were conducted using a high-frequency reciprocating rig, HFRR (PCS Instruments, UK) (Fig. 1). This is a computer-controlled reciprocating friction and wear testing device widely employed to assess the performance of fuels and lubricants. It can operate in either high-stroke length mode (amplitude ca $0.3 \mathrm{~mm}$ to $2 \mathrm{~mm}$ ) or low-stroke length mode (amplitude ca $20 \mu \mathrm{m}$ to ca 0.3 $\mathrm{mm}$ ) and the latter mode, characteristic of fretting, is selected by adjusting a lock on the oscillating shaft. This lock has the effect of increasing the stiffness of the system to enable oscillation to be controlled at low amplitude.

The HFRR uses a linear variable displacement transformer (LVDT) sensor which allows the electronic unit to monitor the motion of the pushrod that holds the upper specimen and adjusts the frequency and amplitude of the vibrator as necessary. Attached to the lower specimen is a piezoelectric force transducer that measures the friction force generated between the two specimens as they slide relative to each other. This force transducer is much stiffer than the flexible supports and this ensures that the friction force appears at the transducer rather than at the supports. Both sensors have test point ports on the circuit boards and in the current study, signals were recorded from these ports using an oscilloscope to plot fretting loops and identify the regime of fretting wear.
Table 2 Test specimen properties

\begin{tabular}{ll}
\hline Ball and disc material & $\begin{array}{l}\text { LESCALLOY® 52,100 VAC- } \\
\text { ARC@ high performance bear- } \\
\text { ing steel }\end{array}$ \\
Ball hardness (HV) & 880 \\
Disc hardness (HV) & 772 \\
Ball roughness, $\mathrm{Ra}(\mathrm{nm})$ & 5 \\
Disc roughness, $\mathrm{Ra}(\mathrm{nm})$ & 5.1 \\
\hline
\end{tabular}

Table 3 HFRR fretting wear test conditions

\begin{tabular}{ll}
\hline Load $(\mathrm{N})$ & $3.92(0.4 \mathrm{~kg})$ \\
Mean contact pressure $(\mathrm{GPa})$ & 1.03 \\
Nominal contact diameter $(\mu \mathrm{m})$ & 87 \\
Frequency $(\mathrm{Hz})$ & $20,80,100,150,200$ \\
Stroke length $(\mu \mathrm{m})$ & 50 \\
Test temperature $\left({ }^{\circ} \mathrm{C}\right)$ & 30 \\
Test duration $($ number of cycles) & 576,000 \\
\hline
\end{tabular}

In a test, a 6-mm diameter steel ball was loaded and reciprocated against the flat surface of a stationary steel disc in dry conditions or immersed in lubricant. Table 2 shows the specimen properties. The HFRR test conditions are listed in Table 3. The stroke length used in all tests was $50 \mu \mathrm{m}$. This was less than the theoretical Hertz diameter of $87 \mu \mathrm{m}$ so the classical requirement for fretting of the amplitude being smaller than the contact diameter, and thus neither surface being fully exposed during reciprocation was fulfilled. Tests were conducted for a fixed number of cycles so as to all experienced the same sliding distance. This means that the low frequency tests lasted longer than those at high frequency. All tests were carried out at a controlled temperature of $30{ }^{\circ} \mathrm{C}$ and at least two repeat tests were carried out at each test condition. For each test, the friction coefficient was determined from the mean absolute value of the force measured by the force transducer throughout the test.

\subsection{Characterisation of Wear}

After completion of a fretting experiment, the specimens were rinsed lightly with toluene and isopropanol solvents to remove supernatant lubricant. Physical cleaning was avoided so as not to remove any debris adhered to the surface. 
Optical images of the ball and disc wear scars were obtained with a Hirox RH-2000 digital microscope to observe the scar and any products on the surface. The Hirox RH-2000 is an optical digital microscope using a high-intensity LED light source for true colour reproduction. To evaluate the topography further and measure the wear volumes, a scanning light interferometry (SWLI) microscope Wyko model NT9100 was used. The microscope was set in vertical scanning interferometry (VSI) mode, calibrated to measure rough surfaces with a nanometre detection range. For the samples contained ZDDP, $0.05 \mathrm{wt} \%$ solution of ethylenediaminetetraacetic acid (EDTA) was applied for $40 \mathrm{~s}$ on the rubbed surfaces to remove any ZDDP anti-wear film on the surfaces since this can interfere with optically based wear measurement.

\section{Experimental Results}

\subsection{Effect of Frequency on Fretting Wear in Dry and Lubricated Conditions}

Figure 2 shows the fretting wear images of ball and disc specimens after 576,000 cycles at $80 \mathrm{~Hz}$ (a 2-h test) in dry conditions (relative humidity was ca $30 \%$ ). Oxidised debris with a characteristic dark brown (cocoa) colour has been produced and has accumulated around the wear scars.

A series of different reciprocation frequencies were applied with the base oil (BO) lubricated contact (Fig. 3). It is clear from Fig. 3 that introduction of a lubricant results in a decrease in wear scar diameter, so that the wear is not as severe as in dry conditions. The wear scars at 20 and $80 \mathrm{~Hz}$ appear darker than the rest, suggesting oxidative wear and the formation of iron oxide, while at higher frequencies the scars become more metallic and typical of adhesive wear and scuffing. Figure $4 \mathrm{a}$ shows the corresponding wear volumes measured using SWLI. Wear volumes range between $2 \times 10^{3}$ and $2 \times 10^{4} \mu^{3}$, with no particular trend of wear volume with frequency. Figure $4 \mathrm{~b}$ shows that friction coefficient increases with frequency. The wear volumes removed from ball specimens are higher than the discs for all frequencies even though the ball specimen is $100 \mathrm{HV}$ harder than the disc.

Frequencies of $20 \mathrm{~Hz}$ and $80 \mathrm{~Hz}$ were chosen to investigate the effect of additives on fretting wear and to investigate if there is any effect of ZDDP and dispersant on wear. However, before introducing additives to the base oil, fretting loops were obtained by recording the signal of the LVDT and the force transducer using an oscilloscope. This was to observe the fretting characteristics and to confirm that the motion of the surfaces falls within the gross slip regime and there is no stick behaviour. Figure 5a shows how the displacement and the tangential force vary with time at the end of a 2-h test (after 576,000 cycles) and Fig. 5b shows a fretting loop determined from those cycles at $80 \mathrm{~Hz}$. In Fig. 5a, it can be seen that as the ball specimen moves from a displacement of $25 \mu \mathrm{m}$ towards the centre of stroke, the friction force increases to reach a maximum at the centre of the motion. As the upper specimen continues to move towards $-25 \mu \mathrm{m}$, the tangential force decreases rapidly, reaching zero at the end of the stroke. Friction then continues to decrease as the upper specimen moves back towards the centre of stroke and finally it increases to become zero at the other end of the stroke. It is interesting to observe that the friction force varies during sliding between the two extremes of motion. The fretting loop (Fig. 5b) shows a typically observed frictional loop in the gross slip regime. The area of the loop corresponds to the dissipated energy during a given cycle and is responsible for material deformation that promotes fretting wear [46]. To clarify Fig. 5a further, Fig. 6 shows how tangential force and ball velocity vary during reciprocation. The instantaneous ball velocity is calculated at each time step from the change in displacement divided by the time step and, since this displacement is small, is only approximate. However the curves do show, as expected, that the friction force increases with sliding velocity to oppose the relative motion of the surfaces.
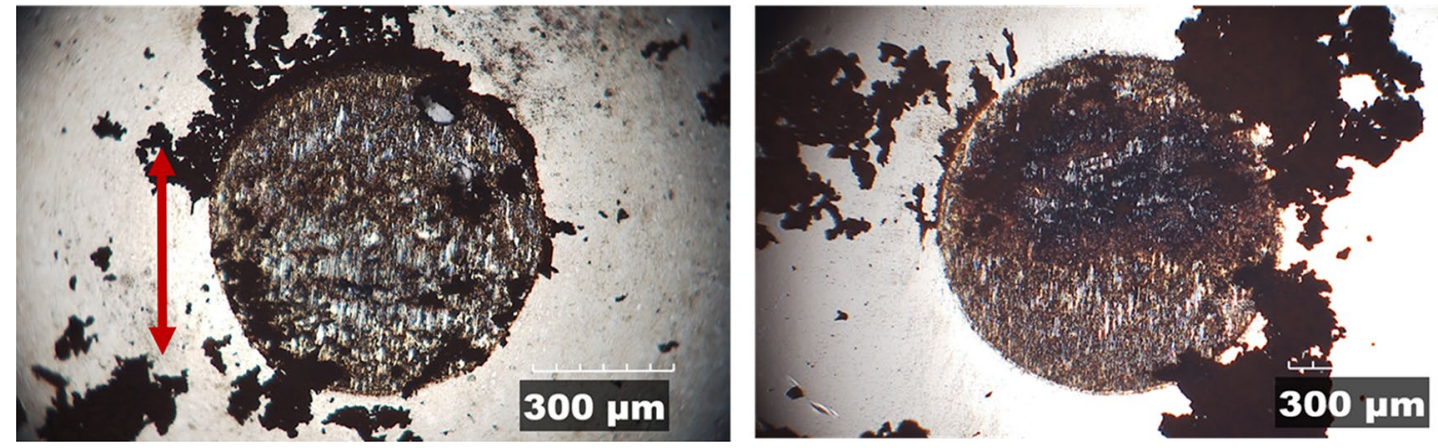

Fig. 2 Optical images of the wear scars on ball (left) and disc (right) specimens in dry conditions at $80 \mathrm{~Hz}$ after 576,000 cycles. (Test temperature is $30^{\circ} \mathrm{C}$. The oscillation direction is from top to bottom and is shown with arrows on the ball specimen.) 
Fig. 3 Optical images of the wear scars on ball and disc specimens using $\mathrm{BO}$ at 20 , $80,100,150$ and $200 \mathrm{~Hz}$ after 576,000 cycles
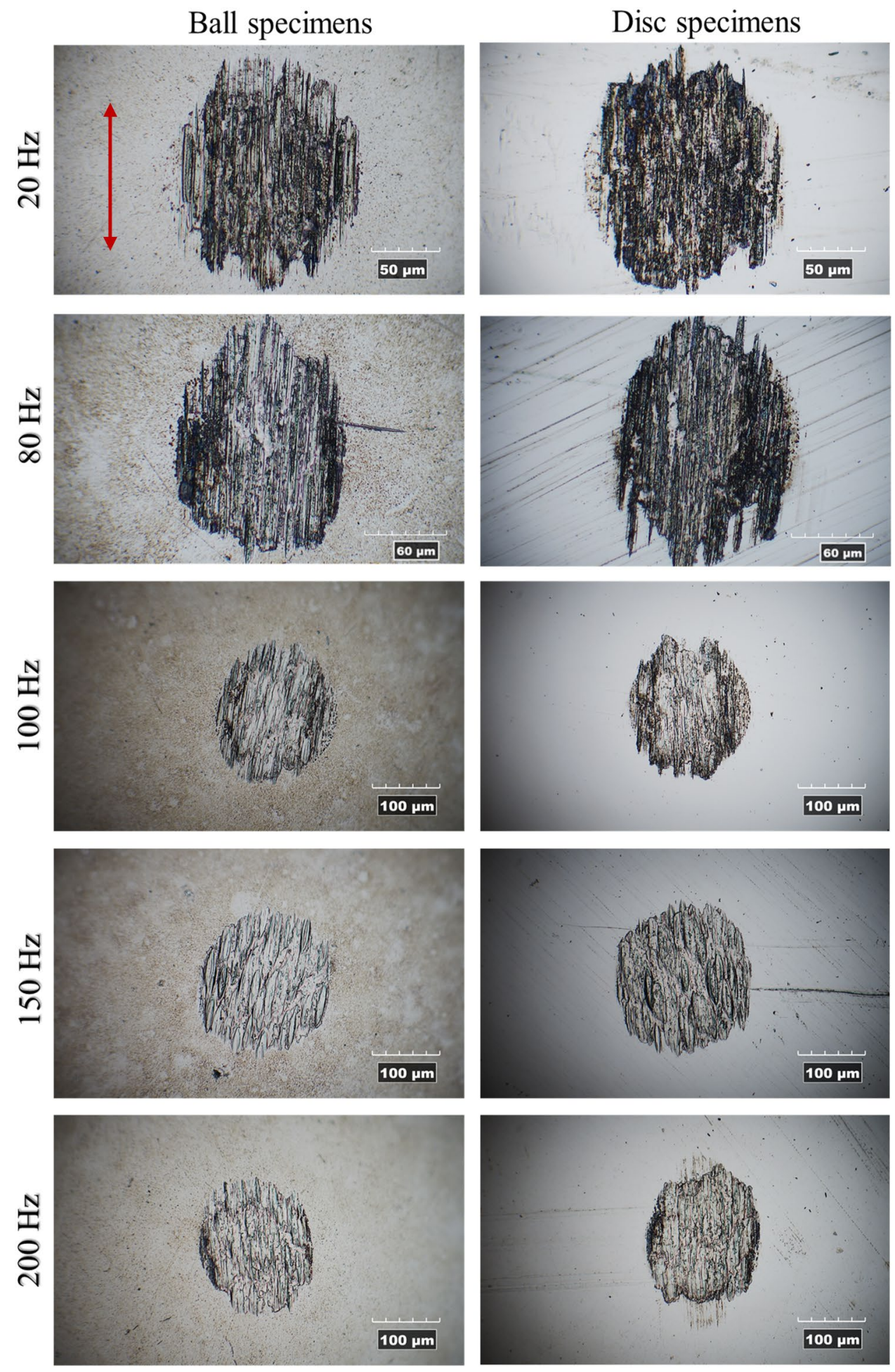

\subsection{Effect of Additives on Fretting Wear}

Figure 7 shows the optical images of the wear scars at 20 and $80 \mathrm{~Hz}$ from tests in dry and lubricated conditions with four lubricants: $\mathrm{BO}, \mathrm{BO}+$ Dispersant, $\mathrm{BO}+\mathrm{ZDDP}$ and $\mathrm{BO}+\mathrm{ZDDP}+\mathrm{Disp}$. In all cases, the wear scars were gently rinsed with solvent, but oxidation debris remained stuck to the surfaces. The wear scar in dry conditions at $20 \mathrm{~Hz}$ is much smaller than the one at $80 \mathrm{~Hz}$ and was probably in the partial slip fretting regime. When lubricant is present, the production of debris is greatly reduced at both frequencies. BO alone gives a dark, oxidised appearance but this is 
Fig. 4 a Wear volume removed from the surface of ball and disc specimens and $\mathbf{b}$ average $\mathrm{COF}$ using $\mathrm{BO}$ at 20,80,100,150 and $200 \mathrm{~Hz}$ after 576,000 cycles
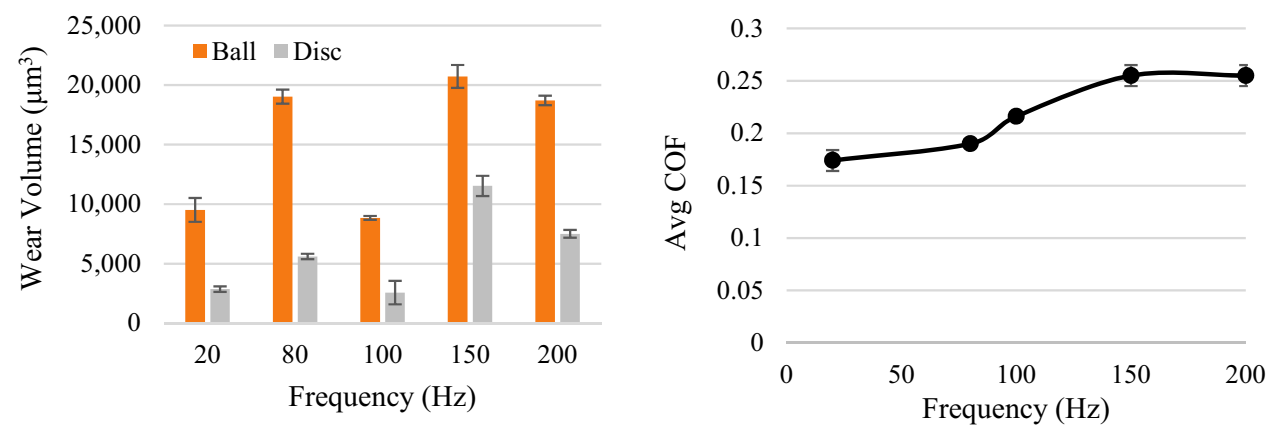

(a) 30

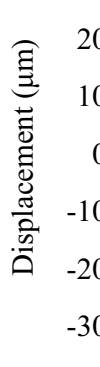

0
0

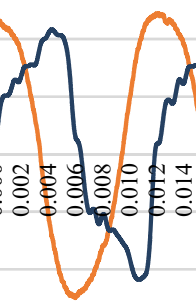

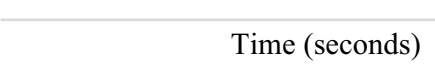

Displacement

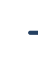

- Tangential Force

1.5

(b)

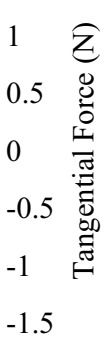

$-1.5$

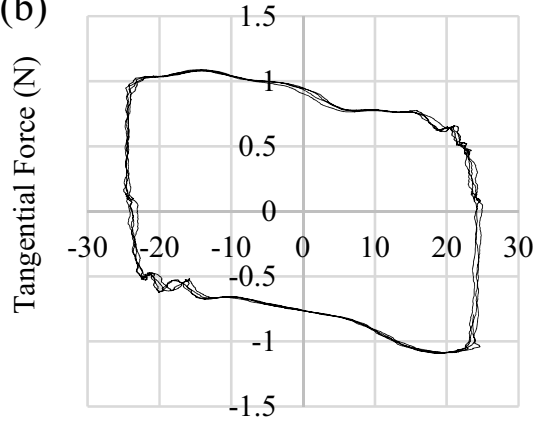

Displacement $(\mu \mathrm{m})$

Fig. 5 a Displacement and tangential force with time and $\mathbf{b}$ fretting loop; both at 576,000 cycles and $80 \mathrm{~Hz}$ in BO

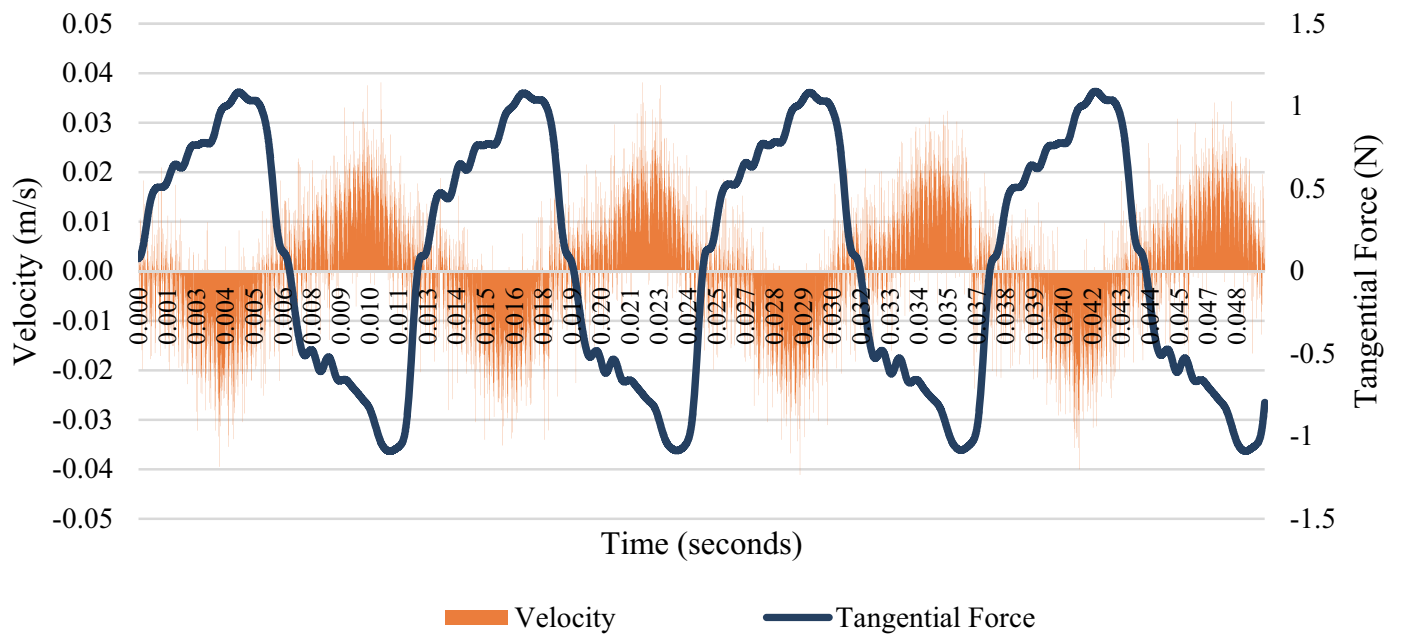

Fig. 6 Variation of sliding velocity and tangential force with time at 567,000 cycles and $80 \mathrm{~Hz}$ in BO

reduced when dispersant is present. Debris seems to collect outside the disc wear scars from BO + Disp at $20 \mathrm{~Hz}$ and both $\mathrm{BO}$ and $\mathrm{BO}+$ Disp at $80 \mathrm{~Hz}$.

The last two rows of Fig. 7 show the formulations containing ZDDP. A typical tribofilm is formed with ZDDP's characteristic plateau-like pads [47]. Figure 8 shows a magnification of the plateau-like pads on ball and disc specimens of tests with BO+ZDDP+Disp at $20 \mathrm{~Hz}$. The disc specimen from the $80 \mathrm{~Hz}$ test shows an area in the middle of the scar without any tribofilm. This is not likely to be due to the formation of an EHD-separating film since the maximum sliding speed at this frequency is ca. $0.01 \mathrm{~m} / \mathrm{s}$ from which the theoretical minimum EHD film thickness is estimated to be $2.4 \mathrm{~nm}$. When dispersant is added to $\mathrm{BO}+\mathrm{ZDDP}$, there is no obvious debris on the specimens and the ZDDP tribofilm pads are less dense than the ones shown without 

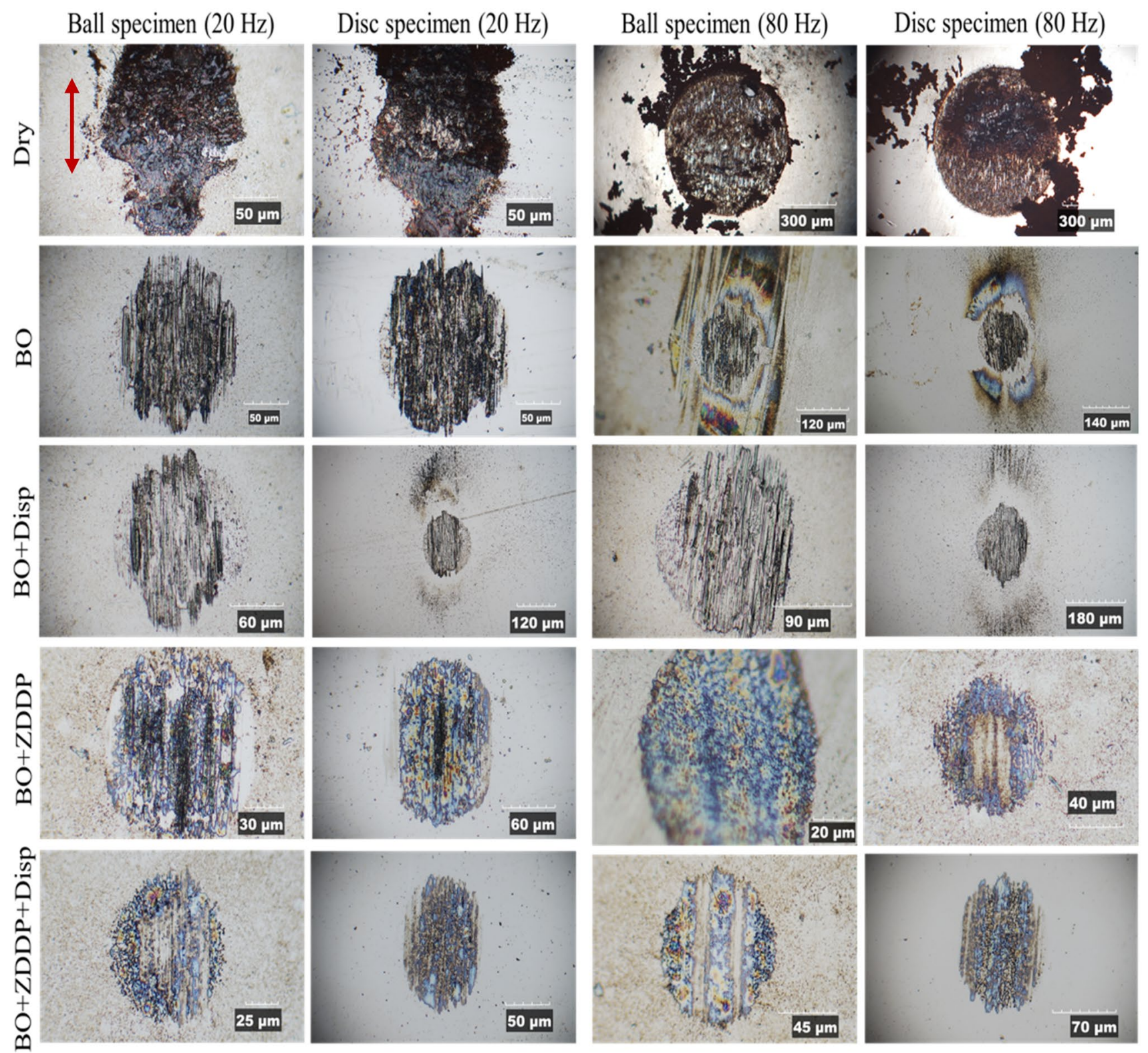

Fig. 7 Optical images of the wear scars on ball and disc specimens at different lubricated formulations at $20 \mathrm{~Hz}$ and $80 \mathrm{~Hz}$ after $576,000 \mathrm{cycles}$. Note that the magnification varies from image to image

the dispersant. It is well known that dispersants reduce the tribofilm-forming capabilities of ZDDP [48].

Figure 9 shows the corresponding wear volumes removed from the surfaces at $20 \mathrm{~Hz}$ and $80 \mathrm{~Hz}$. The trends of ball and disc wear volumes are similar but the ball shows about 5 times more wear than the disc ones for all the formulations. The $\mathrm{BO}+$ Disp shows higher wear volumes than the BO. This is not as expected since dispersants, being polar additives, normally provide a modicum of boundary lubrication. It may reflect the dispersant removing oxidation debris that provides a "third body" layer and protects the surface to some extent in $\mathrm{BO}$ alone. The ZDDP in BO reduces the wear volume on the disc significantly, presumably by forming a tribofilm that protects the surfaces. When dispersant is added, the wear volume is further decreased. ZDDP is much less effective at reducing wear of the ball and this may result from difficulty of ZDDP forming a protective tribofilm on the surface that is always in rubbing contact with the counterface.

Figure 10 shows the mean coefficient of friction (COF) of all the formulations at $20 \mathrm{~Hz}$ and $80 \mathrm{~Hz}$. At both frequencies, the $\mathrm{BO}$ and $\mathrm{BO}+$ Disp show the highest values of $\mathrm{COF}$, ranging from 0.17 to 0.22 . The $\mathrm{BO}$ at $20 \mathrm{~Hz}$ seems to be decreasing during the last hour, possibly due to the 

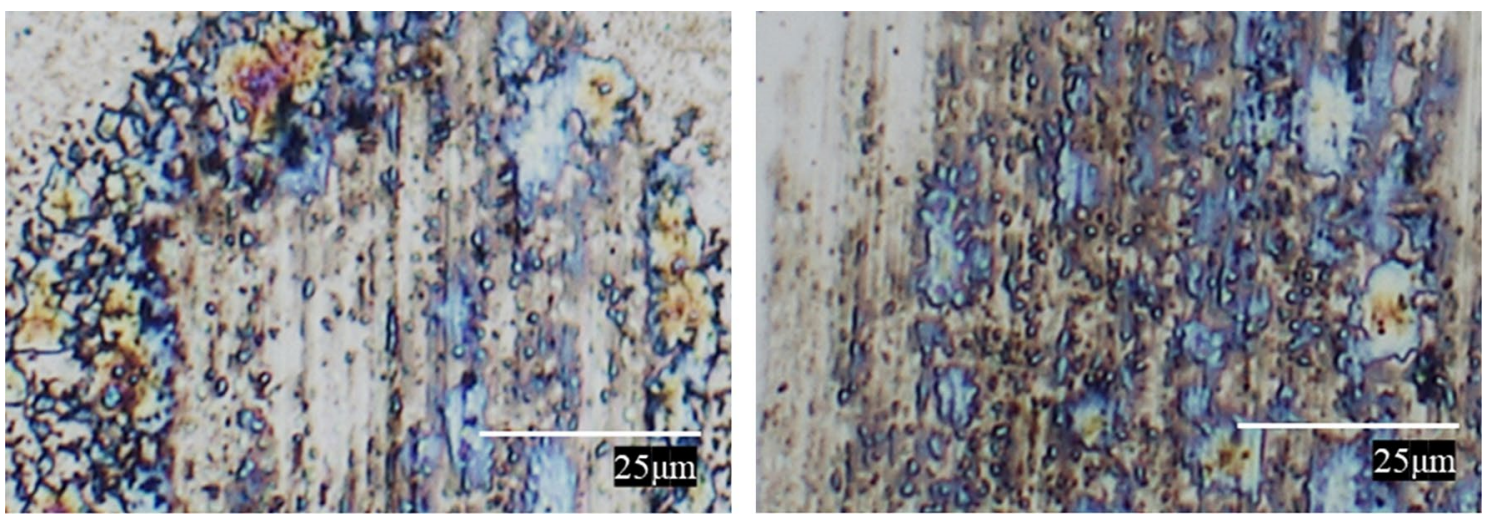

Fig. 8 Plateau-like pads of ZDDP film on ball (left) and disc (right) specimens with BO+ZDDP + Disp at $20 \mathrm{~Hz}$ after $576,000 \mathrm{cycles}$
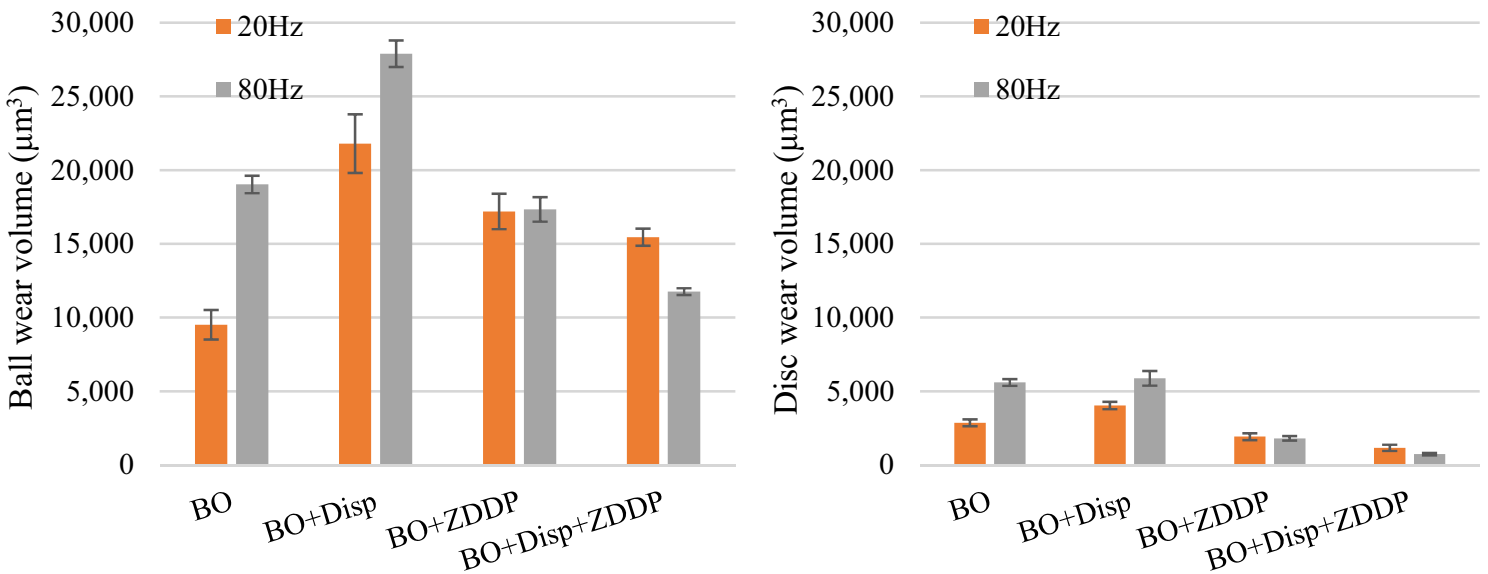

Fig. 9 Ball and disc wear volumes removed at $20 \mathrm{~Hz}$ and $80 \mathrm{~Hz}$ after 576,000 cycles
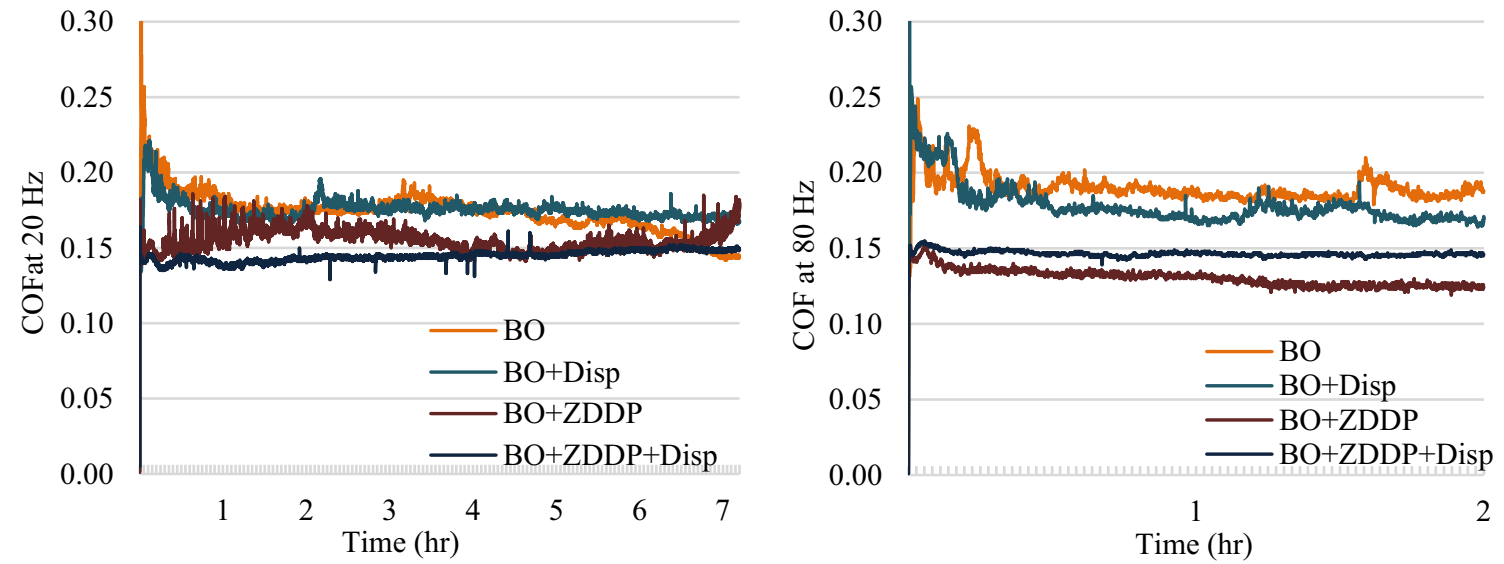

Fig. 10 Coefficient of friction at $20 \mathrm{~Hz}$ and $80 \mathrm{~Hz}$ 
build-up of a debris film, while the $\mathrm{BO}+\mathrm{ZDDP}$ is increasing. $\mathrm{BO}+\mathrm{ZDDP}+$ Disp seems stable for the whole duration of the tests at both $20 \mathrm{~Hz}$ and $80 \mathrm{~Hz}$. BO+ZDDP shows the lowest COF.

\subsection{Effect of Dispersant Concentration}

A higher concentration of dispersant was used to observe if this could further influence the wear behaviour. As shown in Fig. 11, there is no significant change in wear scar appearance except at $0.1 \mathrm{wt} \%$ of $\mathrm{N}$ at $80 \mathrm{~Hz}$, where the scars appear darker.

Figure 12 shows the corresponding wear volumes removed from the ball and disc specimens with $\mathrm{BO}$,
$\mathrm{BO}+$ Disp at 0.02 and $0.1 \mathrm{wt} \% \mathrm{~N}$ at $20 \mathrm{~Hz}$ and $80 \mathrm{~Hz}$. In general, the wear volume increases as the dispersant concentration increases. The wear volume at $80 \mathrm{~Hz}$ is greater than that at $20 \mathrm{~Hz}$ in most tests.

\section{Discussion}

\subsection{Effect of Frequency on Fretting Wear in Dry and BO-Lubricated Conditions}

Fretting wear is characterised by the production of oxidised ferrous wear debris in and around the contact that is believed to contribute at least in part to an abrasion process $[15,16$,
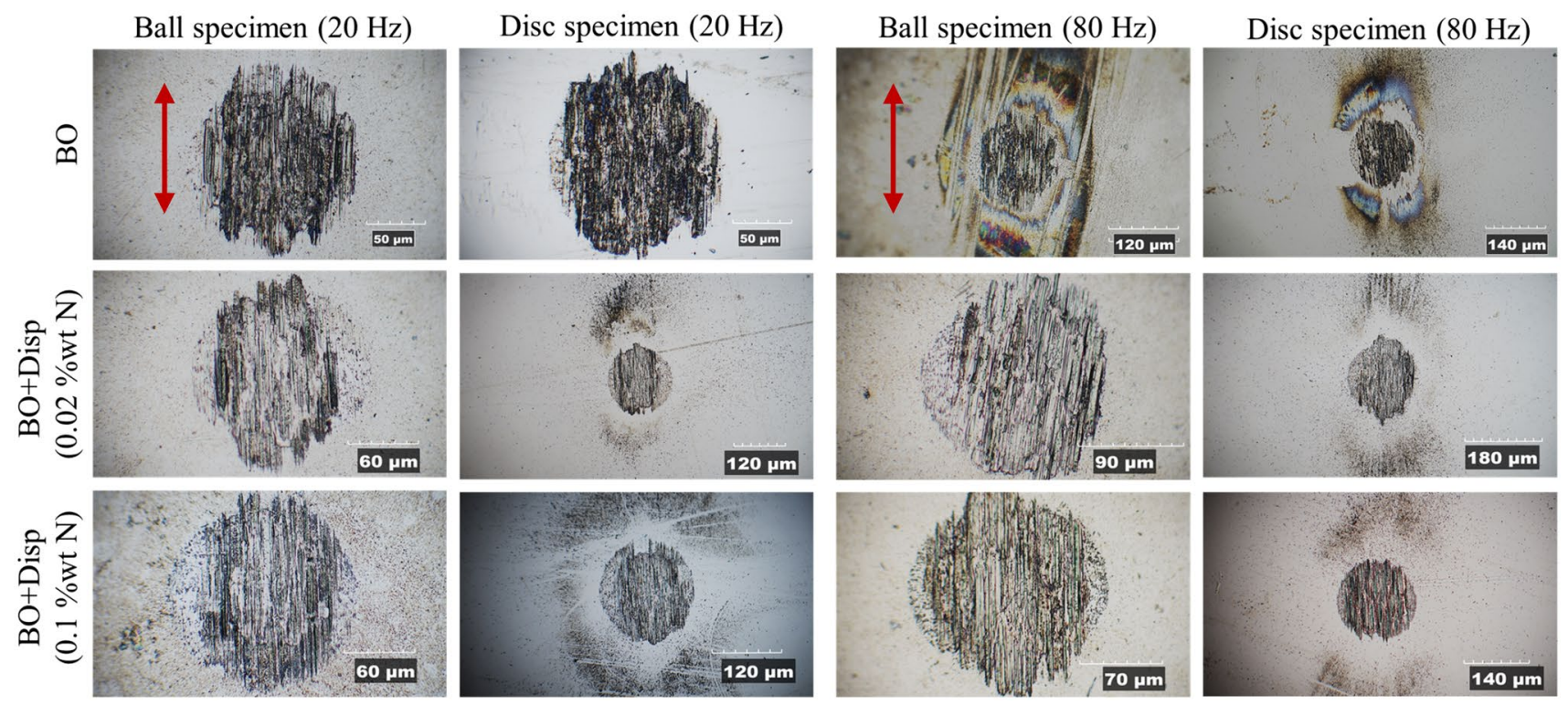

Fig. 11 Optical images of the wear scars on ball and disc specimens at different dispersant concentrations at $20 \mathrm{~Hz}$ and $80 \mathrm{~Hz}$ after 576,000 cycles
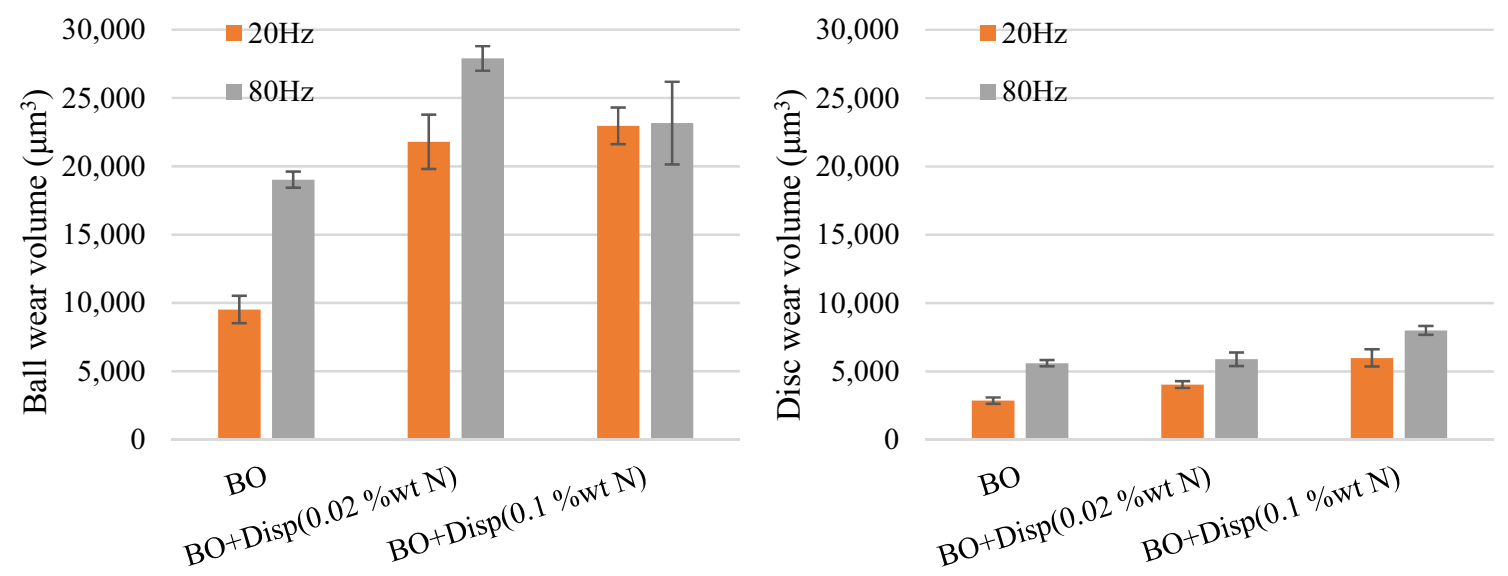

Fig. 12 Ball and disc wear volumes removed using BO and BO+Disp with 0.02 and $0.1 \mathrm{wt} \% \mathrm{~N}$ at $20 \mathrm{~Hz}$ and $80 \mathrm{~Hz}$ after $576,000 \mathrm{cycles}$ 
30]. In dry conditions, this is evident in Figs. 2 and 7. It is also seen at low frequencies when the contact is lubricated by BO, as shown in Figs. 3 and 7, though to a less extent than in dry conditions. However at frequencies greater than $80 \mathrm{~Hz}$, no such particles are seen from BO-lubricated contacts and the surfaces appear shiny and metallic. One explanation is that the higher sliding speeds produced at high frequencies may induce local temperature rise and thus reduction of lubricant viscosity, enabling more lubricant flow than oxygen supply. This is, however, unlikely since the sliding speeds and thus the flash temperatures are very low. The maximum sliding speed in a reciprocating contact is $\pi f$, where $f$ is the frequency and $l$ is the stroke length. Since the stroke length is only $50 \mu \mathrm{m}$, this sliding speed only reaches $0.03 \mathrm{~m} / \mathrm{s}$, even at $200 \mathrm{~Hz}$. This corresponds to theoretical maximum flash temperature rise of less than $4{ }^{\circ} \mathrm{C}$ [49]. Another suggestion, from Jin et al. [26], is that increased fretting frequency reduces the time for oxidation between interactions of the asperities in the contact. The authors consider this to be the most probable cause of this effect of frequency. It should also be noted that since tests were carried out for a fixed number of cycles (and thus a fixed sliding distance), they were much longer at low than at high frequencies, allowing more time for surface oxidation.

As seen from optical and SWLI 3D images of ball wear scars using a BO in Fig. 13, the morphological characteristics of the scars also change with frequency. The $150 \mathrm{~Hz}$ scar shows scuffing characteristics, while the $200 \mathrm{~Hz}$ scar shows scuffing and adhesive behaviour. As it can be seen from Fig. 13, material transfer seems to occur from the disc to ball with higher peaks at $150 \mathrm{~Hz}$ and $200 \mathrm{~Hz}$.

\subsection{Effect of Additives on Fretting Wear}

The influence of dispersant on wear in fretting conditions is complicated in that dispersant clearly reduces the amount of oxidised particulate material in and immediately adjacent to the contact, as shown in Fig. 7, but the actual material damage it produces in terms of wear volume removed is higher than with base oil alone (Figs. 7, 9 ). This may be because the oxidised particle layer acts as a "third body" to protect the surface from adhesive interaction so its removal can be harmful. There may thus be a balance between the abrasive effect of fretting debris and its protective third body effect. Jiang et al. [8] suggested that the formation of a stable layer of debris is affected by the interparticle adhesion force and that temperature plays an important role, affecting the surface free energy of the debris and therefore the adhesive force between them. Although much less oxidised material is seen in and around the contact when dispersant is present, this does not, of course mean that the dispersant is necessarily reducing the production of wear debris; it may simply be preventing it from adhering to the contact surfaces and facilitating its removal from the contact. From Fig. 11, it appears that oxidised debris is still produced when dispersant is present. However this is seen primarily outside the contact as a "halo", as shown more clearly in Fig. 14 that shows the disc wear scar at two magnifications. The higher magnification shows that there is still some debris within and close to the contact while the lower magnification shows that most wear debris has been extruded to well outside the $50 \mu \mathrm{m}$ stroke length.

When dispersant concentration was increased, the wear damage was slightly greater (Fig. 13). The debris at 0.1 wt $\% \mathrm{~N}$ on disc surfaces can be seen to adhere around the wear scar, while at lower concentration and in the BO alone the debris is ejected and adheres only along the line of motion (Fig. 11). One possible explanation is that the dispersant suspends the particles and that the higher viscosity of the oil when dispersant is increased might affect the penetration of oil into the contact. Figure 15 shows the viscosity of the oil measured at different wt $\%$ of dispersant concentrations. The viscosity of the oil increases with increasing $\mathrm{N}$ concentration.

ZDDP in $\mathrm{BO}$ and in $\mathrm{BO}+$ Disp forms a tribofilm that provides protection to the surfaces, reducing the wear rates (Figs. 7, 9). There is some visible oxidation in the $20 \mathrm{~Hz}$ specimens of BO + ZDDP which could be due to the long test of $8 \mathrm{~h}$, allowing the specimens to be exposed to oxygen for a longer period as explained above. When dispersant is present together with ZDDP, there is no obvious material on the specimens and the ZDDP tribofilm pads are less dense than those without the dispersant. The reduced tribofilm formed at the surface result from the well-known antagonism of succinimide polyamine dispersants with ZDDP [50].

The observation that the ball always experiences much greater damage than the disc even though it is harder, as shown in Fig. 9, is striking. This is not generally seen in HFRR tests operating in sliding wear conditions at longer stroke lengths [50] and may thus be specific to fretting conditions. For ZDDP this might be explained by the additive not being able to form a protective film on the surface that is always in contact but the difference is seen even in the absence of ZDDP. One possible explanation is that the debris bed stabilises on the disc and abrades the ball which is always in contact.

Based on the above, ZDDP and dispersant in base oil together would appear to be an effective combination to reduce oxidation and surface damage in fretting conditions. The dispersant may reduce oxidation and help remove solid particles, while the ZDDP provides a tribofilm at the surface to protect it from extending damage. Both coefficient of friction and wear rates were the lowest when this additive combination was used. 


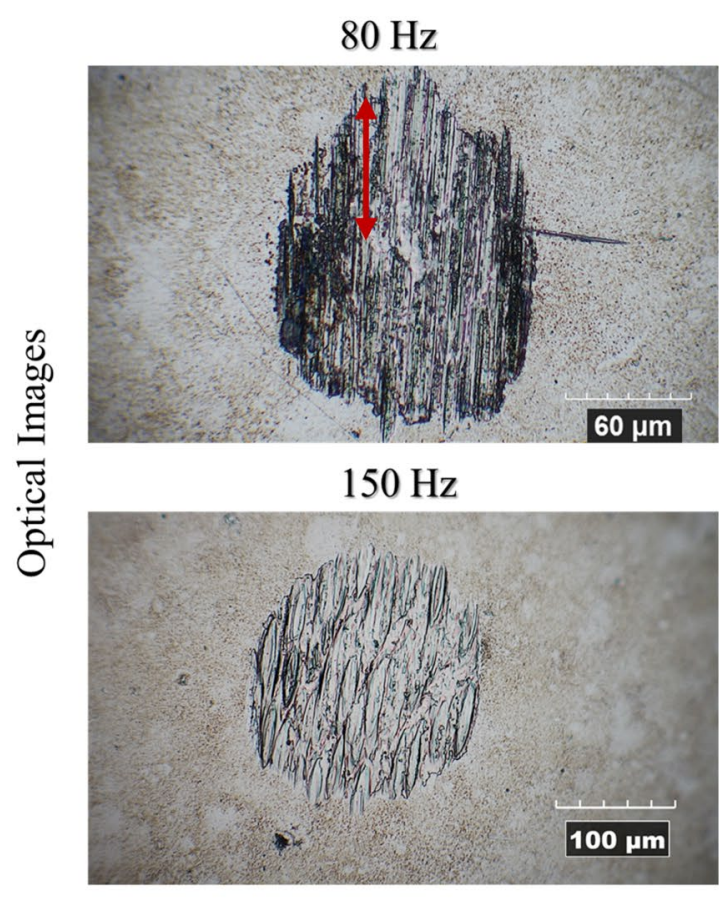

$100 \mathrm{~Hz}$

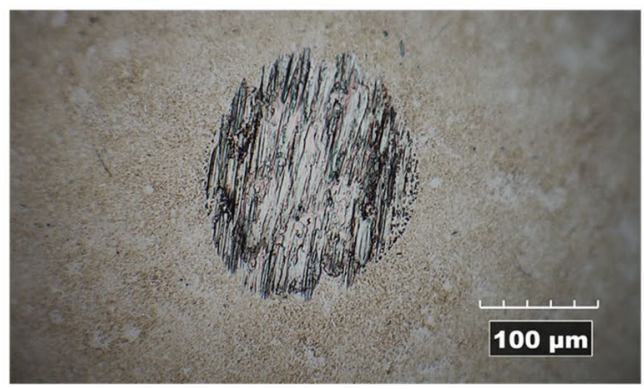

$200 \mathrm{~Hz}$

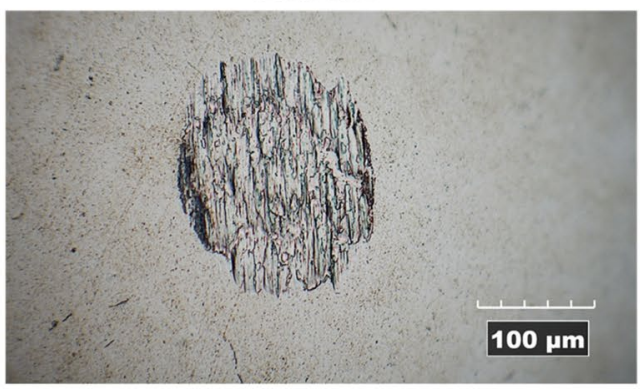

\section{$100 \mathrm{~Hz}$}

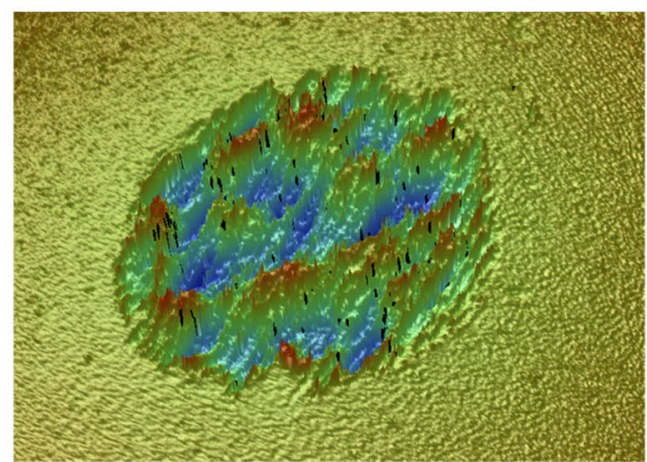

$200 \mathrm{~Hz}$

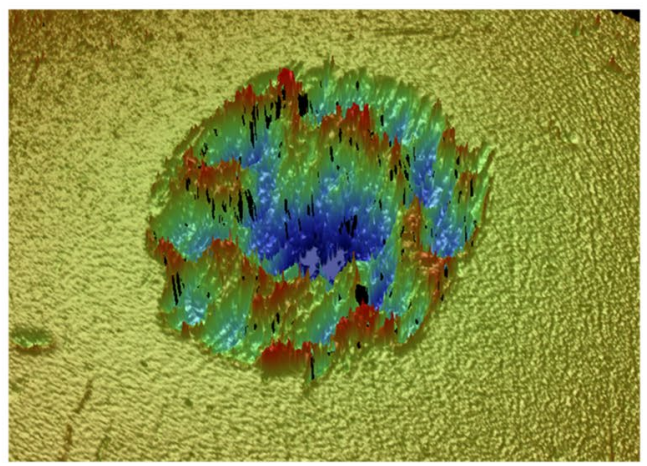

um

1.13

$-0.50$

0.00

$-0.50$

$--1.00$

$-1.50$

$-2.00$

$-2.43$

Fig. 13 Optical and SWLI 3D images of ball wear scars at different frequencies in BO 


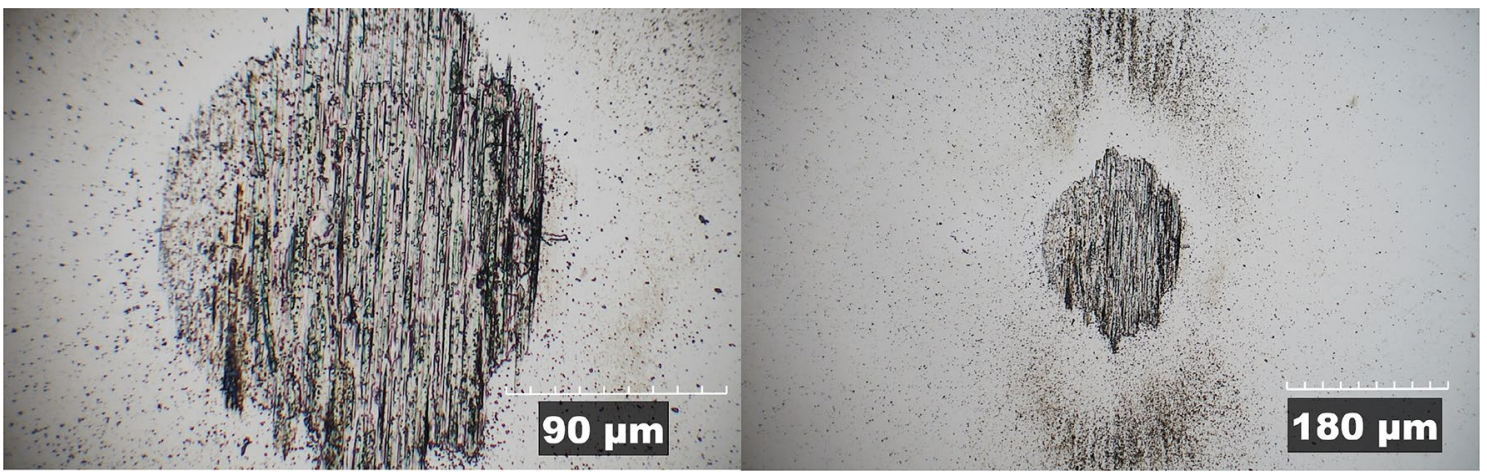

Fig. 14 Wear scar of BO+Disp $(0.02 \mathrm{wt} \% \mathrm{~N})$ on disc specimen at $80 \mathrm{~Hz}$ after 576,000 cycles

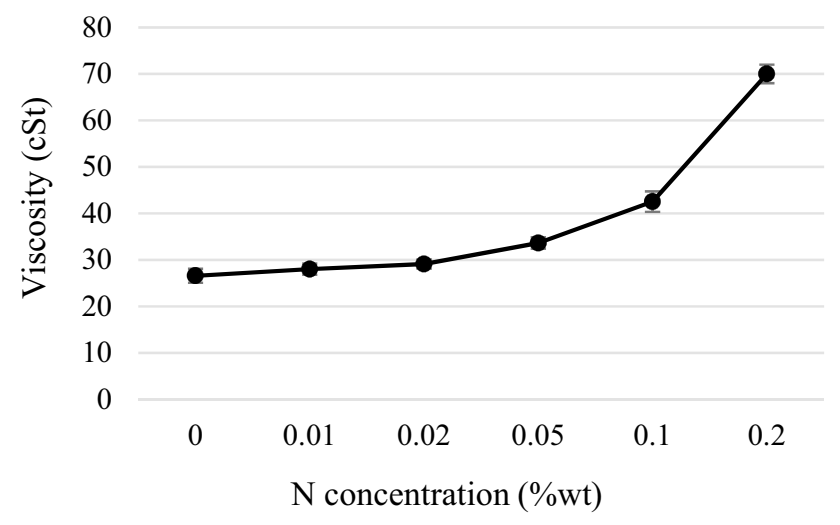

Fig. 15 Viscosity of $\mathrm{BO}+$ Disp at increasing $\mathrm{N}$ concentration at $30{ }^{\circ} \mathrm{C}$

\section{Conclusions}

Ball-on-flat fretting tests have been carried out using a bearing steel contact operating at a very small stroke length of $50 \mu \mathrm{m}$. Wear volumes and friction coefficient were measured and surface characterisation was carried out using optical techniques to investigate fretting wear. The main conclusions drawn from this study are as follows:

- Liquid lubrication reduces particulate build-up and wear rate in low-amplitude reciprocating sliding compared to dry conditions.

- As reciprocating frequency is increased above about $100 \mathrm{~Hz}$, the contact shows a transition from oxidativetype damage to adhesive/scuffing damage with a consequent increase in friction.

- When lubricant is present, much more fretting wear occurs on the ball surface (which is always in contact) than on the stationary disc surface. The reason for this is not clear but it is possible that the debris bed may stabilise on the disc and abrade the ball which is always in contact.

- A succinimide dispersant reduces the production of solid debris but not wear damage. This may be because debris provides some protection of the surfaces.

- The anti-wear additive ZDDP is able to form a tribofilm on the surfaces to reduce wear.

- A combination of dispersant and ZDDP provides a significant reduction in wear in gross slip fretting conditions.

Open Access This article is licensed under a Creative Commons Attribution 4.0 International License, which permits use, sharing, adaptation, distribution and reproduction in any medium or format, as long as you give appropriate credit to the original author(s) and the source, provide a link to the Creative Commons licence, and indicate if changes were made. The images or other third party material in this article are included in the article's Creative Commons licence, unless indicated otherwise in a credit line to the material. If material is not included in the article's Creative Commons licence and your intended use is not permitted by statutory regulation or exceeds the permitted use, you will need to obtain permission directly from the copyright holder. To view a copy of this licence, visit http://creativecommons.org/licenses/by/4.0/.

\section{References}

1. Waterhouse, R.B.: Fretting fatigue. Int. Mater. Rev. 37, 77-98 (1992)

2. Waterhouse, R.B.: Fretting Corrosion. Pergamon Press, Oxford (1972)

3. Godfrey, D.: Fretting corrosion or false brinelling? Tribol. Lubr. Technol. 59(12), 28-30 (2003)

4. Geringer, J., Forest, B., Combrade, P.: Fretting-corrosion of materials used as orthopaedic implants. Wear 259(7-12), 943-951 (2005)

5. Vingsbo, O., Söderberg, S.: On fretting maps. Wear 126, 131-147 (1988)

6. Fouvry, S., Kapsa, P., Vincent, L.: Quantification of fretting damage. Wear 200, 186-205 (1996)

7. Waterhouse, R.B.: Fretting corrosion. Proc. Inst. Mech. Eng. 169, 1157-1172 (1955) 
8. Jiang, J., Stott, F., Stack, M.: The role of triboparticulates in dry sliding wear. Tribol. Int. 31(5), 245-256 (1998)

9. Vaessen, G., Commissaris, C., De Gee, A.: Fretting corrosion of $\mathrm{Cu}-\mathrm{Ni}-\mathrm{Al}$ against plain carbon steel. Proc. Inst. Mech. Eng. Conf. Proc. 183(16), 125-128 (1968)

10. McColl, I., Waterhouse, R., Harris, S., Tsujikawa, M.: Lubricated fretting wear of a high-strength eutectoid steel rope wire. Wear 185(1-2), 203-212 (1995)

11. Liu, Q., Zhou, Z.: Effect of displacement amplitude in oil-lubricated fretting. Wear 239(2), 237-243 (2000)

12. Wright, K.: An investigation of fretting corrosion. Proc. Inst. Mech. Eng. B 1(1-12), 556-574 (1953)

13. Lemm, J., Warmuth, A., Pearson, S., Shipway, P.: The influence of surface hardness on the fretting wear of steel pairs-its role in debris retention in the contact. Tribol. Int. 81, 258-266 (2015)

14. Kayaba, T., Iwabuchi, A.: The fretting wear of $0.45 \% \mathrm{C}$ steel and austenitic stainless steel from 20 to $650^{\circ} \mathrm{C}$ in air. Wear $\mathbf{7 4}(2)$, 229-245 (1981)

15. Colombie, C., Berthier, Y., Floquet, A., Vincent, L., Godet, M.: Fretting: load carrying capacity of wear debris. J. Tribol. 106(2), 194-201 (1984)

16. Godet, M.: The third-body approach: a mechanical view of wear. Wear 100(1-3), 437-452 (1984)

17. Varenberg, M., Halperin, G., Etsion, I.: Different aspects of the role of wear debris in fretting wear. Wear 252, 902-910 (2002)

18. Uhlig, H.H.: Mechanism of fretting corrosion. Trans. ASME J. Appl. Mech. 21, 401-407 (1954)

19. Feng, I.M., Uhlig, H.H.: Fretting corrosion of mild steel in air and in nitrogen. Trans. ASME J. Appl. Mech. 21, 395-400 (1954)

20. Odfalk, M., Vingsbo, O.: Influence of normal force and frequency in fretting. Tribol. Trans. 33, 604-610 (1990)

21. Söderberg, S., Bryggman, U., McCullough, T.: Frequency effects in fretting wear. Wear 110, 19-34 (1986)

22. Uhlig, H.H., Feng, I.M., Tierney, W., McClellan, A.: A Fundamental Investigation of Fretting Corrosion. Technical Note 3029. National Advisory Committee for Aeronautics (1953)

23. Toth, L.: The investigation of the steady stage of steel fretting. Wear 20, 277-286 (1972)

24. Farrahi, G., Markho, P., Maeder, G.: A study of fretting wear with particular reference to measurement of residual stresses by X-ray diffraction. Wear 148, 249-260 (1991)

25. Hirsch, M.R., Neu, R.W.: Temperature-dependent fretting damage of high strength stainless steel sheets. Wear 346, 6-14 (2016)

26. Jin, X., Sun, W., Shipway, P.: The role of geometry changes and debris formation associated with wear on the temperature field in fretting contacts. Tribol. Int. 102, 392-406 (2016)

27. Kalin, M., Vižintin, J.: Comparison of different theoretical models for flash temperature calculation under fretting conditions. Tribol. Int. 34, 831-839 (2001)

28. Ashby, M., Abulawi, J., Kong, H.: Temperature maps for frictional heating in dry sliding. Tribol. Trans. 34, 577-587 (1991)

29. Greenwood, J., Alliston-Greiner, A.: Surface temperatures in a fretting contact. Wear 155, 269-275 (1992)

30. Jin, X., Shipway, P., Sun, W.: The role of frictional power dissipation (as a function of frequency) and test temperature on contact temperature and the subsequent wear behaviour in a stainless steel contact in fretting. Wear 330, 103-111 (2015)
31. Waterhouse, R.: Fretting wear and fretting fatigue at temperatures up to $600^{\circ} \mathrm{C}$. AGARD Conf. Proc. 461, 8.1-8.12 (1989)

32. Hurricks, P.: The fretting wear of mild steel from 200 to $500 \mathrm{C}$. Wear 30, 189-212 (1974)

33. Warmuth, A., Sun, W., Shipway, P.: The roles of contact conformity, temperature and displacement amplitude on the lubricated fretting wear of a steel-on-steel contact. R. Soc. Open Sci. 3(10), 150637 (2016)

34. Lu, W., Zhang, P., Liu, X., Zhai, W., Zhou, M., Luo, J., Zeng, W., Jiang, X.: Influence of surface topography on torsional fretting wear under flat-on-flat contact. Tribol. Int. 109, 367-372 (2017)

35. Pereira, K., Yue, T., Wahab, M.A.: Multiscale analysis of the effect of roughness on fretting wear. Tribol. Int. 110, 222-231 (2017)

36. Kubiak, K., Mathia, T., Fouvry, S.: Interface roughness effect on friction map under fretting contact conditions. Tribol. Int. 43(8), 1500-1507 (2010)

37. Kubiak, K., Liskiewicz, T., Mathia, T.: Surface morphology in engineering applications: influence of roughness on sliding and wear in dry fretting. Tribol. Int. 44, 1427-1432 (2011)

38. Spikes, H.: The history and mechanisms of ZDDP. Tribol. Lett. 17, 469-489 (2004)

39. Zhang, J., Spikes, H.: On the mechanism of ZDDP antiwear film formation. Tribol. Lett. 63, 1-15 (2016)

40. Habeeb, J., Stover, W.: The role of hydroperoxides in engine wear and the effect of zinc dialkyldithiophosphates. ASLE Trans. 30, 419-426 (1986)

41. Rounds, F.: Effects of hydroperoxides on wear as measured in four-ball wear tests. Tribol. Trans. 36, 297-303 (1993)

42. Belin, M., Martin, J., Mansot, J.: Role of iron in the amorphization process in friction-induced phosphate glasses. Tribol. Trans. 32(3), 410-413 (1989)

43. Neyman, A., Sikora, J.: Grease effect on fretting wear of mild steel. Ind. Lubr. Tribol. 60, 67-78 (2008)

44. Sato, J., Shima, M., Sugawara, T., Tahara, A.: Effect of lubricants on fretting wear of steel. Wear 125, 83-95 (1988)

45. Grahn, M., Naveira-Suarez, A., Pasaribu, R.: Effect of ZDDP on friction in fretting contacts. Wear 273, 70-74 (2011)

46. Fouvry, S., Liskiewicz, T., Kapsa, P., Hannel, S., Sauger, E.: An energy description of wear mechanisms and its applications to oscillating sliding contacts. Wear 255, 287-298 (2003)

47. Kontou, A., Southby, M., Spikes, H.: Effect of steel hardness on soot wear. Wear 390, 236-245 (2017)

48. Kontou, A., Southby, M., Morgan, N., Spikes, H.A.: Influence of dispersant and ZDDP on soot wear. Tribol. Lett. 66, 157 (2018)

49. Greenwood, J.A.: An interpolation formula for flash temperatures. Wear 150, 153-158 (1991)

50. Zhang, J., Yamaguchi, E., Spikes, H.A.: Comparison of three bench tests to quantify mild wear. Tribol. Trans. 56, 919-928 (2013)

Publisher's Note Springer Nature remains neutral with regard to jurisdictional claims in published maps and institutional affiliations. 